\title{
PROGRAMAS SOCIAIS NO BRASIL: um estudo sobre o Programa Bolsa Família no interior do Nordeste brasileiro
}

\author{
Clóvis Roberto Zimmermann* \\ Gepherson Macêdo Espínola **
}

\begin{abstract}
O Programa Bolsa Família continua sendo motivo de divergências no Brasil, seja por suas premissas, seja no que tange à diminuição da pobreza, o valor do benefício, a exigência das condicionalidades, os erros de inclusão, o beneficiamento político, as "portas de saída", dentre outros. Em virtude disso, o presente artigo se propõe a estudar o Bolsa Família em nível local, pautado na percepção dos beneficiários. Ao final, são discutidos os resultados da pesquisa, indicando a necessidade de maior investimento na qualidade da educação e da saúde pública brasileira. O estudo também sugere que talvez seja o momento de repensar as condicionalidades. Ao invés de controlar os beneficiários, os governos deveriam melhorar a qualidade da saúde e da educação, bem como articular programas complementares, especialmente os de acesso ao trabalho.
\end{abstract}

Palavras-chave: Programas sociais. Avaliação. Bolsa Família.

\section{O BOLSA FAMÍLIA: consensos, po- lêmicas e desafios}

O desenho institucional do Programa Bolsa Família tem suscitado, no decorrer do tempo, intensos debates que transbordam o mundo intelectual e se expandem para toda a sociedade. Diversos aspectos são colocados em pauta, seja o impacto real sobre a diminuição da pobreza, o valor do benefício, a exigência das condicionalidades, os erros de inclusão, o beneficiamento político, a sustentabilidade do programa, as "portas de saída", dentre outros.

Soares, Ribas e Osório (2010) constataram que o Bolsa Família contribuiu para a redução da desigualdade e da extrema pobreza no Brasil. Suas pesquisas revelam que o Pro-

\footnotetext{
* Doutor em Sociologia pela Universidade de Heidelberg, Alemanha. Docente do Programa de Pós-Graduação em Gestão de Políticas Públicas e Segurança Social da Universidade Federal do Recôncavo da Bahia (UFRB). Coordenador do Programa de Pós-Graduação em Ciências Sociais da Universidade Federal da Bahia (UFBA).

Estrada de São Lázaro, 197. Federação. Cep: 40210-730. Salvador - Bahia - Brasil. clovis.zimmermann@gmail.com

* * Mestre pelo Programa de Pós-Graduação em Gestão de Políticas Públicas e Seguranca Social da Universidade Federal do Recôncavo da Bahia (UFRB).

Rua Dr. Djalma Rocha Galvão, s/n. Centro. Cep: 44.550.000. São Felipe - Bahia - Brasil. gepherson@hotmail.com
}

grama teve uma participação de 21\% na queda registrada no índice de Gini, sendo responsável pela diminuição de $12 \%$ na pobreza (hiato da pobreza) e de $19 \%$ na severidade da pobreza. Na redução das desigualdades, o benefício se configura como a segunda renda mais importante para as famílias, sendo superada apenas pelos rendimentos do trabalho.

Admite-se que a queda da desigualdade, explícita pelo declínio do índice de Gini, está primordialmente atrelada ao comportamento dos rendimentos do trabalho, decorrente da política de valorização do salário mínimo em termos reais, da expansão do mercado de trabalho formal, da estabilidade e do crescimento econômico. Por outro lado, considerando o baixo percentual despendido pelo governo federal com os programas de transferência condicionada de renda, ${ }^{1}$ Kerstenetzky (2009) advoga que o impacto e a relevância do Bolsa Família na redução da pobreza e desigualdade são mais significativos do que os rendimentos do trabalho.

1 Conforme dados oficiais do Ministério do Desenvolvimento Social e Combate à Fome (2012), os dispêndios financeiros com o Bolsa Família correspondem a apenas $0,4 \%$ do Produto Interno Bruto (PIB) do país. 
Entre os estudiosos, é óbvia a contribuição do Bolsa Família para a melhoria imediata das condições de vida. Apesar de o valor transferido ser insuficiente para o provimento das necessidades básicas, considerando uma cesta de bens e serviços, o benefício é de uma relevância enorme para as famílias em situação de pobreza, primordialmente para aquelas que não percebem nenhuma renda fixa ou ela é muito baixa. Zimmermann (2010) endossa que o Bolsa Família se converteu em um mecanismo de enfrentamento da fome no Brasil, uma vez que proporciona, pelo menos, o acesso a uma alimentação mínima a muitas famílias pobres.

Bither-Terry (2012) defende que os baixos valores transferidos são insuficientes para provocar uma saída da pobreza, embora o Programa tenha conseguido reduzir a severidade da pobreza e possibilitado o acesso às necessidades básicas a muitas famílias. Do mesmo modo, para Kerstenetzky (2009, p. 56-57), o benefício ajuda a diminuir a desigualdade de renda, mas não tem a mesma potência para enfrentar a pobreza devido ao baixo valor transferido: “[...] as famílias elegíveis, classificadas como muito pobres ou pobres, recebem transferências em razão da intensidade da pobreza e do número de crianças na família, mas as transferências não são suficientes para remoصê-las da condição de pobreza".

จํ. Ainda em se tratando do valor do benefício, Zimmermann (2010) afiança que o valor da da transferência deveria ser suficiente para કீं prover não só as necessidades alimentares, $\checkmark$ como também o consumo de determinados Ұ bens e serviços considerados básicos numa s sociedade, possibilitando um padrão de vida $\therefore$ adequado. Desse modo, propõe que o valor do $\stackrel{\infty}{\sim}$ benefício seja estipulado com base no custo da

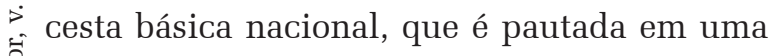
ração essencial mínima, calculada pelo Departamento Intersindical de Estatística e Estudos Econômicos (DIEESE).

A exigência de pré-condições para o usufruto do benefício pela população pobre também é alvo de controvérsias. A cobrança de condicionalidades no desenho da política é justificada sob a alegação de que haveria um estímulo ao acesso de direitos sociais básicos nas áreas da saúde, educação e assistência social, o que, em longo prazo, supostamente possibilitaria às crianças e adolescentes das famílias pobres níveis mais elevados de escolaridade e de saúde, aquisições consideradas fundamentais para a ultrapassagem do ciclo da pobreza e emancipação das famílias. No entanto, ressoam argumentações que questionam as condicionalidades embasadas no caráter punitivo, na falta de garantia da universalidade dos direitos sociais, no problema do acompanhamento dessas áreas e na real efetividade das ações.

Dentre as condicionalidades exigidas para o usufruto do benefício, cabe à assistência social a função de encaminhar crianças e adolescentes vulneráveis e (ou) em situação de trabalho infantil aos serviços socioassistenciais e (ou) de convivência e fortalecimento de vínculos. Também é responsabilidade da assistência social acompanhar as famílias que apresentem dificuldades em cumprir as contrapartidas da educação e saúde e auxiliá-las a superar essa condição.

Para Estrella e Ribeiro (2008, p. 628), as condicionalidades são capazes de aumentar a capacidade produtiva, sobretudo no Brasil, onde "[...] o acesso aos bens e serviços de educação e saúde de qualidade são fortemente concentrados, o que acaba reforçando a enorme desigualdade existente no país”. Para esses autores, a gestão deve focar mais na qualidade dos serviços públicos de educação e saúde disponibilizados aos beneficiários do que nos próprios serviços. Propõem um redesenho das condicionalidades a fim de interromper o ciclo da pobreza.

De acordo com Licio, Mesquita e Curralero (2011), o monitoramento das condicionalidades ajuda o governo a localizar as famílias em situação de maior vulnerabilidade e que encontram barreiras para usufruir dos serviços sociais básicos. Mourão e Jesus (2012) também fazem uma apreciação positi- 
va das condicionalidades, uma vez que elas ensejariam a ampliação das oportunidades de exercício da cidadania por parte dos beneficiários. Contudo, reconhecem que a punição das famílias que não cumprem as regras destoa da proposta de promoção social do Programa. O reforço pretendido nas áreas de saúde e educação, com vistas à interrupção da pobreza, ainda não foi alcançado pelo país.

Noutra acepção, Zimmermann (2010), Kerstenetzky (2009) e Bichir (2010), a partir de distintas arguições, criticam as condicionalidades por seu caráter punitivo. Esses autores condicionam a efetividade delas em relação à falta de qualidade dos serviços prestados, denunciando a falta de punição ao próprio governo no caso da falta ou da carência na oferta adequada dos serviços. Defendem a incondicionalidade da transferência diante da irrestringibilidade dos direitos sociais. Por isso, se considerarmos a obrigação estatal na provisão dos serviços públicos, a exigência de contrapartidas para frequentar esses serviços constitui-se uma contradição com essa obrigação.

Avaliando o desempenho do Bolsa Família nas áreas em que exige condicionalidades, Soares, Ribas e Osório (2010) concluem que o programa teve uma contribuição positiva na educação - na frequência escolar - sem ter um impacto negativo na participação do mercado de trabalho, muito embora não tenham sido registradas contribuições relevantes na área da saúde, fato explicado pelos autores pela carência e precariedade na oferta de serviços públicos.

O monitoramento das condicionalidades de saúde é mais complexo do que o da educação, que se baseia apenas na frequência escolar.

A partir do final de 2008, as condicionalidades de educação foram monitoradas por 85\% dos beneficiários, e as condicionalidades de saúde foram monitoradas por 59\% dos beneficiários, revelando que o acompanhamento das condicionalidades de saúde é muito mais difícil (Soares, Ribas e Osório, 2010, p. 175).

Adicionalmente, Lindert e outros (2007) ventilam que a apuração das contrapartidas na área da saúde é precária, uma vez que não há uma definição precisa sobre a frequência, o número de exames de pré-natal e consultas requeridos. Na prática, o número de visitas aos serviços de saúde é menor do que o necessário, contudo, os trabalhadores da área tendem a compensar essas faltas e encaminhar a frequência majorada.

Outra contenda que circunda o Bolsa Família consiste nos prováveis erros de inclusão, ou seja, vazamentos. Há a disseminação da ideia de que muitas famílias, mesmo fora do perfil do Programa, são beneficiadas indevidamente. Isso leva a crer que famílias em real situação de necessidade, principalmente as que se encontram avassaladas pela miséria, necessitam ficar na fila à espera do benefício. Um dos fatores que concorrem para isso é a omissão da renda auferida no mercado informal, tendo em vista ser a autodeclaração a fonte de informações, o que conduz a distorções na seleção das famílias pela SENARC/MDS. ${ }^{2}$

Kerstenetzky (2009) argumenta que seria mais prudente avaliar o grau de exclusão do que os erros de inclusão. Haveria uma quantidade grande de pessoas excluídas do acesso ao Programa, pois a quantidade de beneficiários de cada município era, até pouco tempo atrás, estimada com base nos dados do IBGE, sendo que, quando a cota municipal era alcançada, nenhuma família, por piores condições que apresentasse, era incluída (Zimmermann, 2010). Existe uma suspeita de que nem todas as pessoas que atendem aos critérios de elegibilidade são atendidas pelo Programa, gerando uma subcobertura, um erro de exclusão. Isso pode explicar os motivos pelos quais havia mais de 16 milhões de brasileiros vivendo na extrema pobreza no ano de 2010.

Segundo Kerstenetzky (2009), o erro

${ }^{2}$ Os três níveis de governo dividem responsabilidades com a gestão do Programa; no entanto, cabe especificamente ao ente municipal, dentre outras funções, efetuar o cadastramento das famílias pobres, manter as informações atualizadas e fiscalizar o cumprimento das contrapartidas. Uma vez que os dados são inseridos no sistema operacional do Programa pelo ente municipal, o ente federal seleciona as famílias e concede os benefícios com base em metas de atendimento e disposição orçamentária. 
de exclusão também está relacionado ao não comparecimento das pessoas pobres aos órgãos governamentais ou locais para declarar sua situação de vida. A falta de noção e de informação sobre os critérios de acessibilidade aos seus direitos de cidadania ocasionaria isso. Os mais pobres também são os mais difíceis de serem encontrados, uma vez que mudam muito de trabalho, de endereço etc. Além disso, o cadastramento é um retrato estático, portanto não capta as oscilações da renda, tampouco os riscos da pobreza. Em virtude disso, alguns autores, como Marques (2008), Silva (2010) e Zimmermann (2010), defendem que esse tipo de Programa deveria ser universalizado, tornando-se uma renda básica de cidadania.

Numa linha convergente, Soares, Ribas e Osório (2010) asseguram que os programas de transferência de renda enfrentam um trade -off entre a extensão da cobertura e a melhoria da eficiência na segmentação. Consideram dificílimo expandir um programa sem aumentar os vazamentos. Para ilustrar essa argumentação, comparam o Bolsa Família ao Programa Oportunidades, programa mexicano de transferência condicionada de renda, que tem uma focalização mais acurada, mas, em compensação, contempla um número menor de famílias. A despeito dos erros de inclusão, constatam 으 que o Bolsa Família, de fato, seria bem foca亏े. lizado, uma vez que $66 \%$ da renda transferida vão para os $10 \%$ de famílias mais pobres. Um dos desafios do Bolsa Família, segundo Mouđ̛̃ rão e Jesus (2012), é estar acessível a toda a $\rightarrow$ população elegível.

I Avultam-se as críticas ao uso eleitoreiro @ do Bolsa Família. Moura (2007) faz apreciaa ções negativas do Programa, relacionando-o às ๙ apelações político-partidárias que elegeram o $\dot{\Delta}$ Programa como símbolo da campanha eleitoral (marketing). De acordo com Zucco (2011), os benefícios eleitorais do Bolsa Família, no curto prazo, são claros e evidentes. Afirma que a reversão do Programa não é uma alternativa politicamente viável, dada a sua aceitação e relevância para as camadas pobres da sociedade e os seus impactos positivos sobre a extrema pobreza.

De outro ângulo analítico, Kerstenetzky (2009) afirma que não existem evidências do uso clientelista do Programa, dado que a descentralização na gestão possibilita muitas informações públicas e transparentes. Complementarmente, Ávila (2010) atesta que, ao estabelecer uma relação direta com os beneficiários, sem intermediários, o Bolsa Família eliminaria qualquer tipo de beneficiamento social e político nos processos-chave do Programa - entrada, permanência, recepção dos benefícios e saída -, coibindo o uso local para fins clientelistas.

As relações entre os pobres e o governo são diretas, sem intermediação, e distantes, considerando-se a impessoalidade institucional presente na comunicação e interação entre autoridades e beneficiários. A intermediação é mínima e altamente institucional, acarretando baixos níveis de compra e coação de voto (Hevia de La Jara, 2011a).

Registra-se uma convergência analítica quando se avalia o impacto do Bolsa Família na economia local, dado o aumento da circulação de dinheiro, o que contribui para o crescimento do município. As transferências auxiliam a economia em períodos de crise, ajudam na manutenção do nível de consumo (eleva a propensão a consumir) e possibilitam o desenvolvimento socioeconômico do país (Mourão e Jesus, 2012). Para Estrella e Ribeiro (2008), as transferências têm forte correlação com a situação socioeconômica do município, ou seja, quanto mais pobres o município possui, mais recursos são transferidos, o que estimula o comércio local e também explicitaria a boa focalização do Programa.

Finalmente, ecoa o maior desafio e uma das maiores questões do Bolsa Família, e talvez a mais crítica: as "portas de saída”. Em outras palavras, a pretensão do Programa em retirar as famílias da situação de pobreza.

Kerstenetzky (2009) ressalta que a falta de perspectivas concretas de inserção social 
não só dos beneficiários, mas também dos ele- te defende que:

gíveis, estimula o crescimento e a manutenção da redistribuição por um longo tempo. Santos e Magalhães (2012) enxergam a participação insatisfatória dos beneficiários em programas estruturantes como um dos gargalos para a superação do estado de pobreza pelas famílias. Lindert e outros (2007) acreditam que as famílias somente ultrapassarão as condições de pobreza quando o governo associar ao Bolsa Família a qualificação profissional, a oferta de empregos e outras oportunidades de geração de renda. Enquanto Mourão e Jesus (2012) ponderam que ainda é cedo para o Bolsa Família provocar uma mobilidade social, já que os investimentos são direcionados às crianças e não aos pais.

Sabe-se que o Programa intenciona dotar as famílias de capital humano para o rompimento da linha de pobreza em longo prazo. Para tanto, seria necessário investir sistematicamente na geração de capacidades e na disponibilização de oportunidades laborais efetivas e reais - dimensão que os programas de transferência de renda da América Latina não consideram. Caso contrário, o Programa estará condenado a cumprir tão somente uma função paliativa, que é o seu papel no curto prazo.

Considerando os debates em torno do Bolsa Família, Silva (2010) revela que os impactos na pobreza são limitados e não possibilitam mudanças no padrão de vida dos pobres, fator que secundariza discussões atinentes ao estabelecimento de um bem-estar efetivo e duradouro. De outro modo, Zimmermann (2010), Kerstenetzky (2009) e Marques (2008) defendem a transformação do benefício em um direito do cidadão, uma vez que o Programa é uma política de governo, e não de Estado, o que ocasionaria uma discussão sobre o reajuste no valor do benefício e traria à tona o debate sobre a efetivação da Lei federal $\mathrm{n}^{0} 10.835 / 2004$ que institui a renda básica de cidadania no Brasil, com atenção especial aos pobres e extremamente pobres.

Ao ponderar sobre as avaliações e debates em torno do Programa, Ávila sinteticamen-

\begin{abstract}
Desconsiderando os discursos oficiais positivos (tanto do governo, como de alguns institutos de pesquisa) e os discursos suspeitos, e escutando os que se beneficiam da política, ou seja, favorecendo a visão daquele que recebe, é possível reconhecer outras opiniões, percepções, sentimentos e avaliações do Bolsa Família. Assim, quando observamos a operação do programa, considerando o cotidiano da política, a relação estabelecida pelos beneficiários e os órgãos responsáveis pela gestão do Programa, outros elementos emergem como fonte de investigação (Ávila, 2010, p. 68).
\end{abstract}

Feito este debate sobre alguns pontos mais relevantes que giram em torno do Bolsa Família, em âmbito macro, e considerando a relevância da gestão local na operacionalização da política, como também as peculiaridades das realidades municipais - que conferem à política uma materialização singular, frente à interação entre as dinâmicas social, econômica, política, cultural e institucional -, cabe apreender os resultados e o impacto do Programa em âmbito local. Desse modo, é feita uma tentativa de captação das convergências, distanciamentos e possíveis particularidades entre as avaliações nacionais e os dados locais. Privilegia-se uma avaliação feita a partir da percepção dos beneficiários, inquirindo-os sobre o papel do Bolsa Família na melhoria das condições de vida e na aquisição de capacidades para acurar os objetivos de longo prazo que o programa se propõe a realizar.

\section{PROCEDIMENTOS METODOLÓGICOS}

Esse estudo objetivou captar as especificidades do Bolsa Família no município de São Felipe, na Bahia. ${ }^{3}$ A fim de apurar a

${ }^{3}$ Localizado na Região Econômica e no Território de Identidade do Recôncavo Baiano, o município de São Felipe apresenta uma extensão territorial de 197,90 km2 e distância de $161 \mathrm{~km}$ da capital baiana (SEI, 2010). É considerado um município de pequeno porte e conta com uma população de 20.305 habitantes, sendo que $48,36 \%$ (9.820 pessoas) residem na zona urbana e 51,64\% (10.485 pessoas) na zona rural, conforme dados do Censo Demográfico do IBGE de 2010. Apesar da sua suposta vocação agropecuária - devido à existência de diversas culturas, 
percepção dos beneficiários do Bolsa Família do município de São Felipe, adotou-se como procedimento uma pesquisa de levantamento ou survey amostral, na tentativa de entender a valoração atribuída ao Bolsa Família e suas dimensões (saúde, educação e assistência social). Nesse sentido, a abordagem quantitativa foi selecionada, por possibilitar resultados concisos, precaver distorções e conferir segurança às ilações feitas. Tais escolhas permitirão a elaboração de projeções sobre a realidade local, bem como o estabelecimento de um diálogo com os dados aferidos nacionalmente, o que, por sua vez, ensejará aproximações ou distanciamentos.

A pesquisa foi constituída por meio de uma amostra aleatória simples, sob o contorno não probabilístico. De acordo com o Ministério do Desenvolvimento Social e Combate à Fome (MDS, 2012), existiam, em outubro de 2012, 3.248 famílias beneficiadas pelo Bolsa Família em São Felipe. Calculando estatisticamente o tamanho da amostra, com um erro amostral de $5 \%$ e nível de confiança de $95 \%$, chegou-se à conclusão de que, para a amostra ser representativa, seria necessária a aplicação de 344 entrevistas. Feito o cálculo, as entrevistas foram distribuídas entre os beneficiários da zona rural e da urbana a partir do critério de proporเo cionalidade, conforme distribuição percentual 亏े da população nesses estratos. Assim, foram realizadas 178 entrevistas com beneficiários สี residentes na zona rural e $166 \mathrm{com}$ os da sede ક̊ do município.

‘ com destaque para cana-de-açúcar, mandioca e laranja, a ‡ criação significativa de distintos tipos de animais, majo-

$\dot{2}$ ritariamente avicultura e rebanho bovino -, além de sua

œ extensão e sua população rural, a economia do municí-

$\curvearrowright$ pio é regulada prioritariamente pelo setor de serviços. Em

¿ 2010 o setor terciário foi responsável por $72,18 \%$ do PIB

- municipal, enquanto o primário correspondeu a $12,10 \%$, o

$\stackrel{\infty}{\sim}$ secundário a $10,59 \%$ e os impostos a 5,14\% (IIBGE 2010).

$>$ É importante mencionar que o município conta com 406

ธิ estabelecimentos empresariais, embora muitas empresas

não formalizem o contrato de trabalho, e a remuneração

$\stackrel{\pi}{\perp}$ oferecida não corresponda ao salário mínimo determina-

๘ do por lei. Segundo o IBGE (2010), o mercado de trabalho

local possuía 9.631 pessoas economicamente ativas em

2010 e, nesse universo, 8.944 estavam ocupadas. Entre as

J pessoas que laboravam, somente $11,4 \%$ possuíam carteira

assinada. $26,6 \%$ não possuíam carteira assinada e $32,9 \%$

trabalhavam por conta própria. Os empregadores soma-

vam $1,6 \%$, os servidores públicos $3,6 \%$ e $24 \%$ não aufe-

ษ riam rendimento, trabalhando para o próprio consumo.
A coleta de dados foi feita através de entrevistas com a aplicação de questionários estruturados que inquiriram sobre o perfil socioeconômico das famílias, educação, saúde, assistência social e avaliação do Programa. ${ }^{4}$ Vale ressaltar que, ao serem abordadas, as beneficiárias recebiam explicações sobre a finalidade da pesquisa para então, caso consentissem, serem entrevistadas. Muitas beneficiárias se recusaram a responder mesmo quando se esclarecia que as respostas poderiam ser anônimas e que não teriam qualquer repercussão sobre o usufruto do benefício. O medo de perder o benefício era tácito em alguns casos e muito explícito em outros. Pairava no ar um temor de a pesquisa ser algum instrumento do governo para "cortar o benefício". ${ }^{5}$

Hevia de la Jara (2011a) argumenta que a falta de conhecimento sobre os critérios de seleção do Programa pelos beneficiários possibilita um leque de interpretações equivocadas sobre a concessão do benefício, refletindo a falta de credibilidade no processo e a falta de confiança nas regras públicas. Talvez essas sejam algumas entre as razões e (ou) justificativas para as resistências e desconfianças encontradas.

\section{ANÁLISE DOS RESULTADOS}

A gestão do Bolsa Família em São Felipe é feita pela Secretaria do Trabalho e Ação Social e a instância de Controle Social do pro-

${ }^{4}$ As entrevistas foram realizadas em dezembro de 2012. Com a finalidade de contemplar distintas localidades e garantir a qualidade da amostra, as coletas foram realizadas prioritariamente nas vias públicas, nos locais em que se concentram e transitam muitas pessoas: nas praças públicas, na feira livre e na fila da única lotérica da cidade (único local para saque do benefício no município). De modo complementar, foram feitas entrevistas em algumas residências. Assim, para precaver o enviesamento da pesquisa, foram eleitas localidades que supostamente apresentavam um grande número de beneficiários, em face das condições explícitas de pobreza. As visitas domiciliares são justificadas pela enorme resistência encontrada para a participação na pesquisa.

${ }^{5}$ Vale ressaltar que a resistência encontrada para a realização das entrevistas não comprometeu a amostra inicialmente estabelecida, uma vez que as beneficiárias que se recusaram a responder ao questionário foram substituídas por novas entrevistadas. 
grama é o Conselho Municipal de Assistência Social. O cadastramento das famílias é feito a partir de demandas voluntárias ou espontâneas na própria sede da referida secretaria. Há alguns anos, a gestão do programa optou por não adotar a "busca ativa"6 para fins de cadastramento.

Em 2012, existiam 4.552 famílias cadastradas no Cadastro Único de Programas Sociais (CadÚnico) e, entre essas, havia 3.705 com o perfil do programa, ou seja, com renda per capita familiar de até $\mathrm{R} \$ 140,00$ mensais. Como já foi informado, no município existiam 3.248 famílias beneficiadas naquele ano. $\mathrm{O}$ valor médio dos benefícios transferidos foi de R\$ 118,30. O Gráfico 1, mostra a evolução do número de famílias beneficiadas no município.

Gráfico 1 - Evolução das famílias atendidas pelo Bolsa Família (em mil), São Felipe, 2006-2012

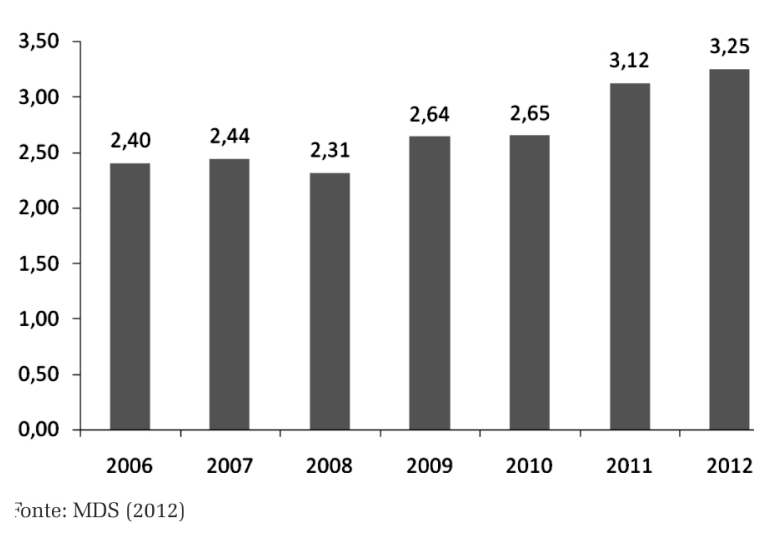

Depreende-se da análise gráfica que, de modo análogo ao comportamento nacional, o número de famílias contempladas pelo benefício, ao longo dos anos, foi ascendente, com exceção de 2008. A evolução registrada reflete a tentativa de o Programa universalizar o benefício entre as famílias elegíveis. Prova disso é que a cobertura ultrapassou a estimativa do Censo, que mostrava a existência de 3.120 famílias com perfil de renda para o Programa.

Inicialmente, com a intenção de captar

${ }^{6}$ A "busca ativa" é uma ação que consiste na procura, identificação e inclusão de pessoas ou famílias pobres e extremamente pobres no Cadastro Único dos Programas Sociais do Governo Federal, haja vista a ausência de demanda espontânea para fins de cadastramento. informações relativas às condições de vida dos beneficiários, inquiriu-se sobre o perfil socioeconômico das famílias. Essas informações foram julgadas importantes frente ao reconhecimento de que a pobreza também escapa do critério renda e se materializa em outras formas. Daí a relevância de saber quem são e como vivem os beneficiários, qual a situação do domicílio em que vivem e em que gastam o benefício, por exemplo.

\section{Perfil socioeconômico}

Entre as 344 pessoas entrevistadas apenas $36(10,47 \%)$ não eram as titulares do benefício, mas compunham o arranjo familiar dos beneficiários. No universo pesquisado, $97,09 \%$ das entrevistas foram feitas com beneficiários do gênero feminino, o que representa 334 pessoas. $^{7}$ Apenas 10 homens responderam às questões $(2,91 \%$ dos entrevistados). A pesquisa atestou que o benefício é comumente gerido por mulheres, que se responsabilizam e decidem sobre a aplicação dos recursos. Villatoro (2010), apoiado em estudos do Banco Mundial, informa que, quando as transferências são entregues às mulheres, elas adquirem maiores responsabilidades, capacidade de negociação e assumem um papel protagonista na família.

Tendo como pressuposto a autodeclaração sobre raça ou etnia, 90,41\% das entrevistadas se declararam pardas (180 pessoas) e negras (131 pessoas), 7,56\% brancas e 0,87\% amarelas. Ninguém se declarou indígena e $1,16 \%$ afirmou pertencer à outra etnia. Não se deve olvidar que a pobreza, na sociedade brasileira, tem íntima relação não só com o desenvolvimento desigual e concentrado, como também com a exclusão social que historicamente aprofundou, intensificou e reproduziu as más condições de vida, sobretudo dos ne-

${ }^{7}$ Em virtude dessa estatística, toda e qualquer referência relativa a quem recebe o benefício, a partir daqui, será feita no feminino. 
gros. A pobreza possui um forte componente étnico-racial que se interconecta com o passado de barbárie e escravidão e se materializa, no presente, com as oportunidades desiguais. Os níveis e os padrões de emprego, bem como as remunerações, traduzem essa discriminação. Os dados do Censo revelam que, no município, os rendimentos auferidos pelas pessoas que se declararam brancas e amarelas são maiores do que o daquelas que se declararam pardas ou negras (IBGE, 2010).

A seguir, é apresentado um resumo das características das famílias entrevistadas. A partir da análise, depreende-se que a pobreza, no município, tem um forte componente educacional - 54,36\% das beneficiárias são analfabetas, alfabetizadas ou possuem ensino fundamental incompleto. Esse dado indica que a educação formal da maioria das responsáveis pela família foi preterida. Não se pode olvidar que o grau de escolaridade é um entre os fatores determinantes de mobilidade social e de uma boa colocação no mercado de trabalho. A questão habitacional parece não ser um dos grandes problemas da população pobre no município, ao menos do grupo entrevistado.

Os dados atinentes à situação no mercado de trabalho, de um lado, revelam a baixa inserção das pessoas acometidas pela pobreza em atividades produtivas remuneradas ㄱ. 44,48\% são donas de casa, do lar ou desempregadas. Vale dizer que a maior proporção das

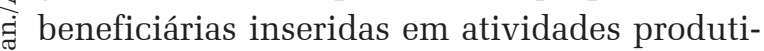
fi vas tem como ocupação o trabalho rural, sendo que $34,01 \%$ laboram para a autossubsistência I. ou para terceiros. As empregadas representam, ふَ juntas, apenas 9,59\%, e as autônomas 10,47\%, a sendo que, nesses grupos, a incidência maior é

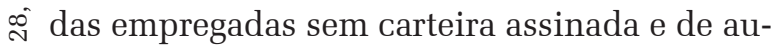
tônomas sem previdência social. Além disso, $1,45 \%$ das entrevistadas são aposentadas ou pensionistas.

Ao inquirir as beneficiárias desempregadas (88 entrevistadas) sobre o motivo da falta de ocupação, 67,05\% informaram que faltam vagas ou oportunidades no mercado, $12,50 \%$ alegaram a baixa escolaridade, 11,36\% apontaram a remuneração não atrativa, 5,68\% assumiram a falta de qualificação profissional, 2,27\% atribuíram a desocupação à crise econômica e 1,14\% se recusou a responder.

Cabe repertoriar que uma das críticas ao Bolsa Família é o fato de o Programa estimular a ociosidade das famílias beneficiárias e desencorajar o trabalho. Para Lindert et al. (2007), o benefício pode ocasionar a recusa de oportunidades de trabalho, haja vista a certeza e a regularidade da transferência, as quais, por sua vez, estimulariam a renúncia a outros rendimentos - baixa propensão de esforço ao trabalho. De outro modo, Zimmermann (2010) atribui essas críticas à estigmatização das beneficiárias, e Bichir (2010) revela que há mais preconceitos do que evidências, dada a inexistência de estudos que comprovem o provável desestímulo.

Pondera-se, no entanto, que, em alguns casos, a percepção de desincentivo, fortemente disseminada e impregnada de preconceito, pode estar relacionada à não aceitação de postos de trabalho ou serviços cuja remuneração é demasiadamente baixa. As famílias pautadas no custo de oportunidade, na relação custobenefício, optam por não aceitar essas propostas. Não se deve esquecer que o sistema de proteção social brasileiro foi tecido tardiamente e que ideias liberais ainda constituem o crivo analítico de muitos. Assim, o direito de escolha dos pobres e a valorização da sua mão de obra, mesmo para serviços pequenos, causam estranhamento.

Ao arguir as entrevistadas se, após o recebimento do benefício, algum membro da família deixou de trabalhar, 97,97\% responderam que não; portanto, não se pode falar que o benefício desestimula o trabalho. Essa estatística corrobora a pesquisa feita por Soares, Ribas e Osório (2010), que releva, em nível nacional, que a taxa de participação dos beneficiários no mercado de trabalho é maior do que a dos não beneficiários.

Considerando o rendimento de todos os 
membros das famílias beneficiárias, sem computar o valor do benefício, os dados atestam que $76,74 \%$ das famílias dispõem de nenhuma renda e até meio salário mínimo mensal para o provimento das necessidades básicas. É perti- lias (Tabela 1). nente elucidar que o salário mínimo estabelecido pelo governo federal não é suficiente para o atendimento de todas as necessidades básicas das famílias, tampouco para a garantia da subsistência e segurança alimentar, considerados os preços reais dos alimentos e o custo de vida. ${ }^{8}$ Reconhecido esse fato e tendo em conta os resultados obtidos na Pesquisa de Campo (2012) pesquisa e o tamanho das famílias, assevera-se que a pobreza, no município, tem uma forte ligação com a ausência e insuficiência de renda. Daí emerge a relevância do benefício, do seu caráter complementar (alívio da pobreza), no suprimento das necessidades alimentares.

Parte muito significativa das beneficiárias, 81,40\%, recebe entre $\mathrm{R} \$ 32,00$ e $\mathrm{R} \$$ 134,00 mensais. Tendo por base o custo de uma cesta de bens e serviços necessários à manutenção da vida, fica evidente que os valores transferidos são demasiadamente baixos para fazer frente às condições de pobreza. A transferência monetária promove um lenitivo nas condições de pobreza, mas não patrocina uma mudança radical de vida.

Levando em conta os valores recebidos, a renda declarada, o tamanho das famílias e o tempo em que a maioria das beneficiárias recebe a transferência, ratifica-se que o Bolsa Família não é capaz de promover a saída da pobreza, consistindo, no entanto, em um bálsamo relevante frente às péssimas condições de vida dos pobres - o que reforça a hipótese deste trabalho.

Como o nível de pobreza no município é elevado e a carência de renda é notória, tor-

${ }^{8}$ O DIEESE, a partir de metodologia própria, calcula o salário mínimo necessário para o provimento das necessidades básicas e atesta que o salário mínimo nominal determinado pelo governo é insuficiente para provê-las. na-se fundamental conhecer em que as beneficiárias gastam os recursos transferidos. Essa questão admitiu múltiplas respostas e dá pistas sobre a saliência do benefício para as famí-

\begin{tabular}{lrr} 
Tabela 1 - Gastos com o benefício (Bolsa Família ), São Felipe, 2012 \\
\hline Despesas & Frequência & \% \\
\hline Alimentação & 307 & 89,24 \\
Medicamentos & 242 & 70,35 \\
Educação & 169 & 49,13 \\
Vestuário (roupas, calçados etc.) & 159 & 46,22 \\
Bens de consumo (eletrodomésticos, móveis, utensílios) & 38 & 11,05 \\
Outros & 23 & 6,69 \\
Sementes ou insumos & 22 & 6,40 \\
Construção ou reparos na habitação & 15 & 4,36 \\
Lazer & 12 & 3,49 \\
\hline
\end{tabular}

As despesas possibilitadas com os benefícios demonstram que $89,24 \%$ das famílias utilizam o benefício para a aquisição de gêneros alimentícios. Chama a atenção que, na sequência, apareçam os gastos com medicamentos, $70,35 \%$, e os gastos com educação, 49,13\%. Os gastos com medicamentos, em tese, deveriam ser de responsabilidade dos entes federados, mas, devido à falta de acesso, oneram os beneficiários do Programa. É curioso constatar que apenas $6,40 \%$ compram sementes ou insumos com o benefício, considerando a extensão territorial rural do município e o número de beneficiárias que se declararam trabalhadoras rurais. Provavelmente, outras necessidades são mais proeminentes do que o investimento na produção. Isso corrobora os estudos de Silva (2010), segundo os quais o impacto do Bolsa Família, devido a seu baixo valor, restringe-se às necessidades imediatas e é incapaz de mudar o padrão de vida das famílias.

Soares, Ribas e Osório (2010) afirmam que as despesas estão intimamente ligadas à percepção das famílias de que o benefício é um bônus a ser gasto prioritariamente com os filhos. Os autores mostram que a maioria das beneficiárias do país gasta o benefício com alimentação, educação e vestuário infantil. Os gastos com saúde não foram afetados pelo benefício em âmbito nacional. Os dados apura- 
dos no município de São Felipe, em relação aos dispêndios com saúde, contrariam os resultados nacionais.

É pertinente não se distanciar da noção de que o Bolsa Família, assim como os demais programas de transferência condicionada de renda em curso na América Latina, intenciona aliviar a pobreza em curto prazo e interromper sua propagação nas gerações futuras. Diante dos dados até então apresentados, pode-se constatar que o programa tem conseguido, em certo grau, cumprir o seu objetivo imediato ao incorporar renda ao orçamento doméstico. Resta saber a percepção das beneficiárias a respeito das áreas em que o programa exige participação com vistas à potencialização do capital humano familiar.

\section{Educação, saúde e assistência social}

Quando a pesquisa apurou se todas as crianças e adolescentes com menos de 17 anos estavam matriculadas na escola, $76,16 \%$ das beneficiárias responderam que os filhos estão regularmente matriculados, enquanto apenas $0,87 \%$ entrevistadas relataram que nem todos os filhos foram registrados em um estabelecimento de ensino. Entre as representantes ouvidas, $22,97 \%$ não possuem filhos nessa faixa etária, ou em idade escolar, o que significa que não são monitoradas pelo Bolsa Família no Gráfico componente educação. Entre as famílias com todos os filhos devidamente vinculados a uma instituição de ensino apenas 1 (uma) possui crianças ou adolescentes œ que não frequentam a escola.

\& $\quad$ Considerando não apenas as famí-

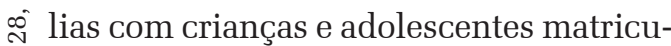
$>$ lados, mas todas as famílias da amostra, foram observados 6,10\% de casos de desistência escolar. Como razões do abandono escolar foram apontadas as seguintes justificativas: desinteresse $(57,14 \%)$, outro motivo (19,05\%), encontrou trabalho $(14,29 \%)$, problemas de saúde $(4,76 \%)$ e Fonte: Fonte: Pesquisa de Campo (2012) dificuldade de aprendizado (4,76\%). Isso suscita a atenção da gestão local do Programa.

A investigação também questionou se as famílias tiveram alguma dificuldade em conseguir vaga na escola pública, e o resultado demonstrou que isso ocorreu em 8,72\% das famílias. Por sua vez, 71,51\% afirmaram que encontram vagas nas escolas sem dificuldade; já para 15,99\% a questão não era aplicável e 3,78\% não responderam. A oferta de vagas na escola pública não parece apresentar grandes problemas, já que o índice de famílias que atestam dificuldades é baixo. O município possui apenas quatro escolas públicas de Ensino Fundamental II e uma de Ensino Médio. Possivelmente, as dificuldades alegadas se relacionem a vagas nessas séries, já que existem 52 unidades escolares de Ensino Fundamental I pulverizadas em todo o território municipal.

A condicionalidade ligada ao componente da educação consiste em manter a assiduidade regular das crianças e adolescentes na escola. Alguns estudos, como o de Soares, Ribas e Osório (2010), atestam que o Bolsa Família teve nacionalmente um impacto significativo sobre a frequência escolar. Convém conhecer a percepção das beneficiárias locais sobre a frequência após a concessão do benefício. Também se julgou relevante interrogar sobre o rendimento escolar depois da transferência. O Gráfico 2 ilustra os resultados.

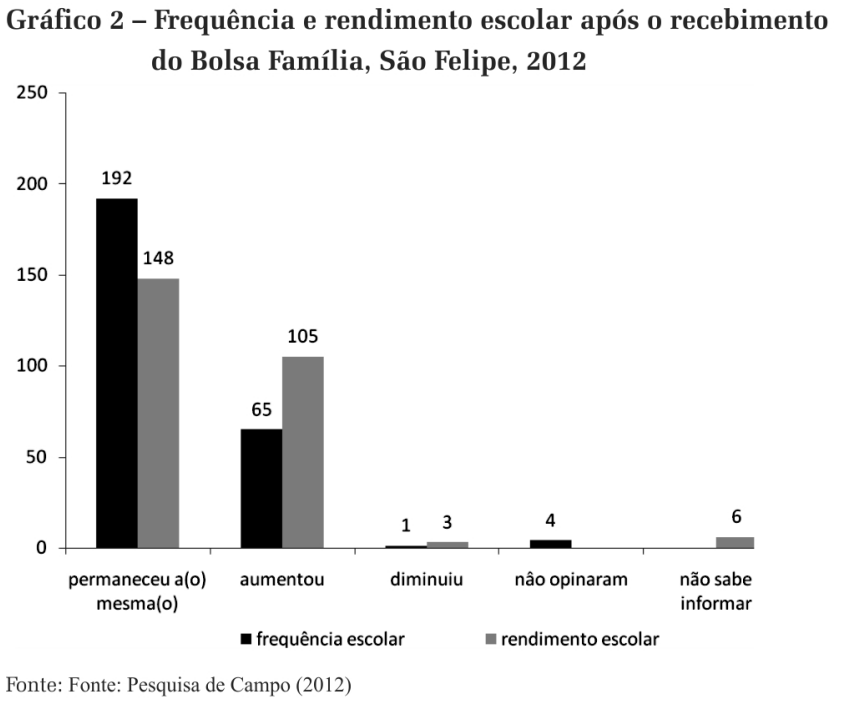


Os resultados comprovam que, em âmbito local, o Programa não altera muito a frequência e muito menos o rendimento escolar, uma vez que $73,28 \%$ das beneficiárias alegaram que a constância escolar se manteve a mesma após o recebimento do benefício e 56,49\% declararam que o rendimento escolar permaneceu inalterado, ou seja, houve pouco impacto na melhoria da vida escolar. Já $32,93 \%$ das beneficiárias alegaram que houve um aumento no rendimento escolar devido ao Bolsa Família. Mesmo assim, a estratégia de utilizar o Bolsa Família para aumentar o rendimento escolar não parece tão eficaz como propagado, ou seja, o salto de qualidade no capital humano com vistas ao rompimento geracional do ciclo da pobreza está longe de se tornar realidade no município de São Felipe.

Apesar de reconhecerem as limitações do Bolsa Família para mudanças efetivas na educação dos pobres e para a interrupção intergeracional da pobreza, Soares, Ribas e Osório (2010) ponderam que a diminuição da evasão escolar tem reinserido, nas escolas, crianças em atraso escolar e que demandam atenção especial. Noutra acepção, Kerstenetzky (2009) realça o papel exercido pela educação como condicionante do sucesso econômico das crianças no futuro, das oportunidades e escolhas. Nesse sentido, advoga a necessidade de melhorar a qualidade da educação além de assegurar creches e ensino infantil de boa qualidade.

Esses dados indicam que o problema da educação em São Felipe está muito mais relacionado com a qualidade do que com a acessibilidade, hoje o principal componente das condicionalidades. Assim, fica evidente que um dos maiores desafios para a educação pública é obter ganhos em qualidade nesse município. Tanto Mourão e Jesus (2012), quanto Estrella e Ribeiro (2008) corroboram essa tese e ressaltam a necessidade de melhoria do serviço. Os últimos propõem, adicionalmente, mudar o foco na taxa de frequência do Bolsa Família visando, sobretudo, ao acompanhamento do rendimento das crianças e adolescentes.
De qualquer forma, os dados do estudo relacionados à educação indicam que mais pesquisas nessa área necessitam ser feitas, possibilitando uma compreensão mais sistemática dos efeitos e impactos das condicionalidades. O exemplo de São Felipe indica que é necessário investir mais na qualidade da educação do que na acessibilidade. Isso significa que se podem repensar as condicionalidades, deslocando-se o foco do beneficiário para os governos federados, que, em última instância, são os responsáveis pela melhoria da qualidade da educação. Com isso, a responsabilidade pelos fracassos pode ser transferida dos indivíduos beneficiados e recair sobre o Estado.

Quando a pesquisa avaliou os componentes de saúde, constatou que 60,47\% das beneficiárias possuíam crianças menores de 7 anos com carteira de vacinação, 3,49\% informaram que seus filhos não possuíam a carteira, o que evidencia o descumprimento da condicionalidade, e 31,98\% das beneficiárias alegaram não ter filhos nessa faixa etária. Ao inquirir se as carteiras de vacinação das famílias que possuem filhos estariam atualizadas, somente 1 (uma) respondeu que estava em atraso $(0,48 \%)$ e 3 preferiram não responder (1,44\%), o que leva a crer que a vacinação estava defasada.

Quanto à acessibilidade aos serviços de saúde, 65,12\% das beneficiárias informaram não possuir dificuldades em acessar os serviços, enquanto que $31,40 \%$ alegaram dificuldades. Mais uma vez, fica evidente que o acesso aos serviços não é um problema das beneficiárias, mas do gestor público, motivo pelo qual o controle das condicionalidades pode alterar o foco do problema. Ou seja, ao invés de investir o tempo no controle da frequência das beneficiárias, o Estado poderia criar mecanismos para monitorar a acessibilidade e a qualidade de seus serviços.

A pesquisa também verificou a frequência de visitas dos agentes comunitários de saúde ou de outros membros do Programa Saúde da Família Os resultados revelam que as famílias beneficiárias possuem uma boa cobertura 
- 87,79\% recebem visitas de algum membro da equipe da saúde na família, no máximo bimestralmente. No entanto, pondera-se que os 11,91\% das famílias beneficiárias não contam com a visita em um período curto, o que, de certo modo, obstrui ganhos na área de saúde pela população pobre.

Os meios utilizados para a aquisição de medicamentos também foram alvo de interesse da pesquisa, admitindo resposta múltipla. Assim, 69,19\% das beneficiárias declararam comprar os medicamentos de que necessitam, $56,69 \%$ os adquirem através da farmácia básica do SUS, 4,36\% recebem amostra grátis e 2 pessoas dependem de doação. Os resultados confirmam e justificam os altos gastos do benefício com medicamentos. Por outro lado, esses dados demonstram a falta de oferta de medicamentos necessários para a manutenção da saúde da família na farmácia básica do SUS.

Como esse trabalho se pauta na percepção das beneficiárias, é primordial ter ciência sobre a opinião delas a respeito da qualidade da alimentação e da saúde da família após a concessão da transferência. Os resultados serão demonstrados a seguir.

Gráfico 3 - Qualidade da alimentação e saúde da família após o Bolsa Família, São Felipe, 2012

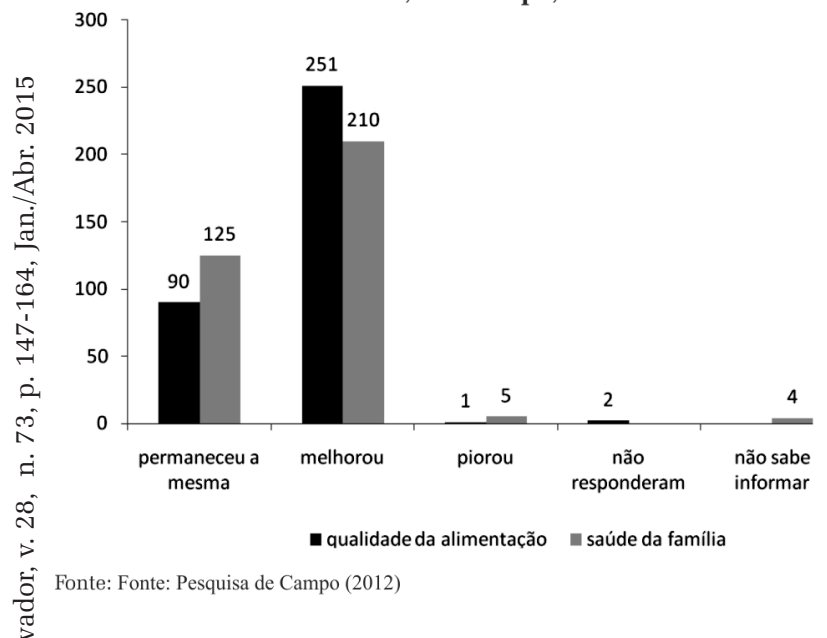

Avaliando a qualidade da alimentação, a maioria das famílias, $72,97 \%$ asseverou que houve melhoria. Essa informação tem uma ilação direta com o fato de que a primeira ordem dos gastos é com gêneros alimentícios.
Deduz-se, inclusive, que a qualidade da saúde mencionada pelas beneficiárias tem uma relação com o incremento das refeições e não com ganhos nutricionais. Conforme autopercepção, $61,05 \%$ ratificam a melhoria na saúde da família. Infere-se que esse entendimento pode ser resultado do complemento alimentar que o benefício proporciona e pela possibilidade de adquirir remédios com os recursos transferidos.

Esses resultados também são encontrados no estudo de Castiñeira, Nunes e Rungo (2009) sobre o Bolsa Família, que em curto prazo não teria apresentado resultados positivos em termos de saúde. As melhoras percebidas no consumo alimentar não teriam qualquer relação com a saúde, e sim com a possibilidade de adquirir mais alimentos. Os autores revelam que não são encontradas diferenças significativas entre a saúde das beneficiárias e das não beneficiárias em situação similar. Propõem mudanças que foquem os hábitos familiares - educação em saúde. Já de acordo com Soares, Ribas e Osório (2010), a ausência de impacto do Bolsa Família na saúde sugere problemas com a oferta dos serviços.

A pesquisa também colheu informações referentes à área da assistência social, não só pela existência de uma condicionalidade na área - crianças retiradas do trabalho infantil ou vulneráveis devem ser inseridas no Programa de Erradicação do Trabalho Infantil (PETI) -, mas principalmente pelo fato de que essa é a pasta que administra o Bolsa Família em âmbito local. Além do mais, a própria orientação da política de assistência social assevera a universalização dos direitos sociais e a proteção e promoção social a toda a sociedade, com destaque singular para aqueles em situação de risco social, vulnerabilidade, pobreza e miséria. Desse modo, as famílias beneficiárias do Bolsa Família constituem um público-alvo em potencial para usufruto dos serviços socioassistenciais e socioeducativos de que a pasta dispõe no município.

Quando as beneficiárias foram questio- 
nadas se algum membro da família participa ou já participou de algum programa e (ou) serviço da assistência social, 54,94\% das entrevistadas responderam negativamente, 43,60\% afirmaram que já tinham participado. Em seguida, indagou-se sobre a participação nos programas e serviços, admitindo-se respostas múltiplas. O Gráfico 4 exibe os resultados.

Gráfico 4 - Participação de beneficiárias do Bolsa Família em programas e serviços da Assistência Social, São Felipe, 2012

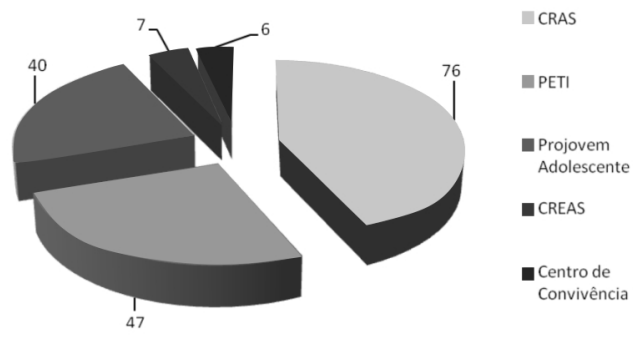

Fonte: Fonte: Pesquisa de Campo (2012)

Como foi demonstrado, as famílias beneficiárias apontaram o Centro de Referência da Assistência Social (CRAS), responsável pela proteção social básica, como unidade pública com maior capilaridade, o que indica a presença dessas famílias em serviços ou programas de proteção e fortalecimento de vínculos. Adversamente, constatou-se uma partici- Gráfico 5 pação tímida, até mesmo irrisória, dos programas e serviços ofertados pelo Centro de Referência Especializado da Assistência Social (CREAS), considerando sua finalidade e sua orientação para a resolução de casos de violação de direitos. Já o PETI teve uma participação razoável na pesquisa, uma vez que está disperso em várias localidades rurais.

Hevia de la Jara (2011b) entende o Bolsa Família como a principal por- Fonte: Fonte: Pesquisa de Campo (2012) ta de entrada para acessar os serviços e programas socioassistenciais, já que, na maior parte dos municípios brasileiros, é a assistência social quem gere o Programa. Licio, Mesquita e Curralero (2011) também aventam uma "forte relação" entre a assistência social e o
Bolsa Família, uma vez que ambos estão sob o comando do mesmo ministério e dividem o lócus institucional de gestão em todos os estados e na maioria dos municípios - além do apoio à gestão descentralizada, que também é possibilitada pelos fundos de assistência social.

Quando se inquiriu às beneficiárias se alguma criança ou adolescente trabalha ou já trabalhou, 10,47\% responderam afirmativamente e $2,62 \%$ relataram que o trabalho foi abandonado após o recebimento do benefício. Esses dados demonstram que o Programa tem pouco impacto na contenção do trabalho infantil. As demais famílias informaram que nunca houve caso de trabalho infantil.

Ao se avaliarem as três dimensões em que o Programa exige contrapartidas, foi questionado se a educação, a saúde e a assistência social já haviam promovido alguma atividade (campanhas, palestras, seminários), especificamente relacionada ao Bolsa Família, a fim de avaliar se a gestão local promove uma integração entre as áreas ou não, bem como se cada área prioriza os debates atinentes ao Programa. O Gráfico 5 apresenta os resultados.

- Realização de atividades especificamente relacionadas ao Bolsa Família nas áreas de educação, saúde e assistência social, São Felipe, 2012

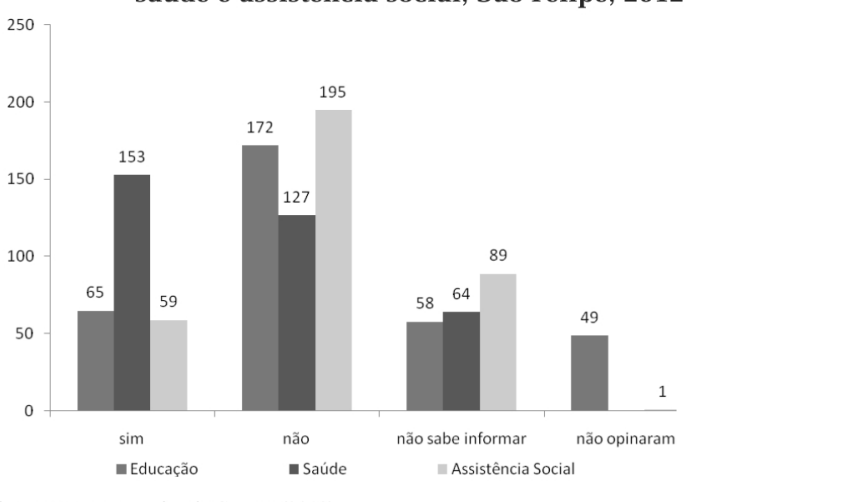

Um alto percentual de pessoas informou que as atividades não existem ou não sabem informar se existem, ou seja, praticamente não existem. A situação mais grave foi a da assistência social, com incidência de $82,56 \%$, se- 
guida da educação com $66,86 \%$ e da saúde com $55,52 \%$. Chama a atenção que a própria secretaria que é responsável por gerir o Programa - e articular a rede de gestores - não direciona atividades especificas para as beneficiárias. Em termos comparativos, somente a saúde obteve um percentual positivo nesse quesito, já que $44,48 \%$ afirmaram que essas atividades existem no setor da saúde.

A partir dos resultados apresentados acima, ficou visível que não há uma preocupação integrada das áreas que compõem as estratégias de articulação do benefício com o oferecimento de atividades específicas. O ponto forte do benefício é seu aporte monetário, o qual, obviamente, possui impactos na qualidade de vida das beneficiárias.

\section{Avaliação do programa}

A pesquisa também colheu informações sobre a suficiência do valor transferido para o atendimento às necessidades básicas das famílias e perguntou diretamente se, após a concessão do benefício, a vida das famílias melhorou.

O Bolsa Família é conhecido por ser um Programa que transfere valores muito baixos, se comparados com a cesta básica ou com o salário mínimo. ${ }^{9}$ A grande maioria das entrevis$\stackrel{2}{\sigma}$ tadas, 79,07\%, respondeu que o valor não é suGráfico 6 - Percepçóes da suficiência do valor do benefício e da melhoria na vida pós Bolsa Família, São Felipe, 2012

${ }^{9}$ Em parte dos países europeus, os programas de transfe○ rência de renda chegam a conceder benefícios no valor de até $70 \%$ do salário mínimo vigente. Nos EUA, valor dos benefícios também é modesto, chegando a cerca de 30\% do salário mínimo. ficiente para o atendimento das necessidades básicas. Por outro lado, 89,24\% das famílias responderam que, mesmo assim, a vida melhorou com o Programa. Deduz-se, com isso, que, embora a transferência seja de valores bastante modestos, o benefício é capaz de auxiliar no abrandamento da pobreza das famílias. Contudo, isso demonstra que o grau de carência de renda e das condições de vida dos pobres no município ainda é muito grande.

Quando as beneficiárias foram interpeladas a respeito do cumprimento das condicionalidades, $81,10 \%$ alegaram que sempre cumprem, 14,24\% alegaram que às vezes cumprem, 4,07\% responderam que raramente ou nunca cumprem as obrigações. Isso não quer dizer que as beneficiárias sejam favoráveis às condicionalidades, mas, como ventila Kerstenetzky (2009, p. 70), “[...] um forte motivo para o cumprimento [das condicionalidades] parece ter sido o medo de perder os benefícios, e não os ganhos esperados em termos das capacitações das crianças".

Apesar de a maioria das beneficiárias aduzir que sempre as contrapartidas do Programa sempre são cumpridas, cerca de um terço, ou seja, $32,93 \%$ admitiram que já foram punidas, seja via advertência, bloqueio ou até suspensão do benefício. Isso demonstra que o direito à cidadania é frágil, sendo que a possibilidade de perda do benefício é perceptível. Ao questioná-las sobre o recebimento de acompanhamento para voltar a cumprir as condicionalidades, 24,25\% beneficiárias afirmaram que tiveram apoio. Contudo, quanto ao apoio prestado às beneficiárias, elas majoritariamente o associavam à prestação de informações dadas pela gestão para voltar a usufruir o benefício.

A fim de captar informações sobre a existência de programas complementares ofertados pela gestão local do Bolsa Família, como programas e cursos de geração de emprego e renda, alfabetização de adultos e cursos profissionalizantes, a pesqui- 
sa interpelou as beneficiárias a esse respeito. Pautando-se nos dados apurados, constatouse que, para $84,30 \%$ das beneficiárias, o município não oferta sistematicamente programas complementares. O resultado explicita a falta de apoio da gestão do Bolsa Família, nos âmbitos local, estadual e federal, no incentivo ao fortalecimento de capital humano pelas famílias beneficiárias. Ao se considerar que, no desenho institucional do Bolsa Família, cabe aos programas complementares o desenvolvimento dessas potencialidades, assevera-se que a ausência desses programas no município contribui para a perpetuação da pobreza em longo prazo.

Para Hevia de la Jara (2011b), a gestão local, via recursos do Índice de Gestão Descentralizada do Bolsa Família (IGD), pode formular programas complementares conforme a realidade local e deixar a sua marca. Licio, Mesquita e Curralero (2011), apesar de reforçarem a obrigação dos três níveis de governo no provimento de programas complementares, realçam o papel da gestão local no desenho desses programas, uma vez que ela usufrui de informações privilegiadas sobre as potencialidades locais. De outro modo, defendem a oferta via Estado como um meio de ampliar sua responsabilidade na gestão do Bolsa Família, dada a sua participação coadjuvante. Já Santos e Magalhães (2012) revelam que os municípios e os estados se envolvem pouco na oferta de programas complementares e ficam à espera da oferta via governo federal.

Face ao reconhecimento amplamente disseminado de que o Bolsa Família ajuda no

Gráfico 7 - Limite de recebimento do Bolsa Família

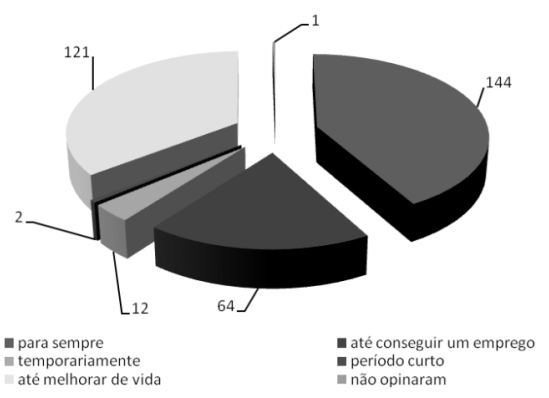

Fonte: Fonte: Pesquisa de Campo (2012) alívio da pobreza, como foi discutido ao longo deste trabalho, convinha arguir sobre o tempo, o prazo em que as beneficiárias acreditam que devem receber a transferência.

A maior fatia da amostra, $41,86 \%$, exteriorizou o desejo de que o benefício deve durar para sempre, corroborando a relevância da transferência condicionada na complementação das necessidades da família. Na sequência com $35,17 \%$, agrupam-se aquelas que limitam o recebimento à melhoria das condições de vida. Apenas 3,48\% das beneficiárias opinaram que o benefício deveria ser temporário, ou seja, com prazo limitado de permanência.

E finalmente, indagou-se a respeito da conceituação da transferência pelas beneficiárias em termos de ser um direito social garantido através do status de cidadania.

Gráfico 8 - Percepção sobre o benefício

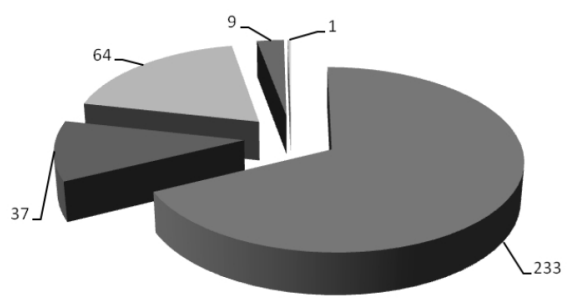

- uma ajuda do governo $\quad$ - dever do Estado um direito

te: Fonte: Pesquisa de Campo (2012)

Evidencia-se que, entre as famílias pobres, a concepção amplamente difundida, $67,73 \%$, é de que o benefício consiste em uma ajuda do governo. Do ponto de vista institucional, as afirmações das famílias estão corretas, uma vez que o Programa não é desenhado na perspectiva dos direitos, além de o benefício ser condicionado, podendo ser cancelado a qualquer momento. Ressalta-se que, no Brasil, a atenção tardia do Estado para a proteção social, por um lado, endossou a estigmatização e, por outro, disseminou a ideia de que os pobres devem se esforçar, por si mesmos, na luta pela melhoria das condições de vida. 


\section{CONSIDERAÇÕES FINAIS}

A transferência condicionada de renda configura, para as famílias beneficiárias de São Felipe, na Bahia, um importante meio de alívio da pobreza, cumprindo o seu objetivo de curto prazo, em consonância com outros estudos feitos em âmbito nacional. A pobreza das famílias beneficiárias é refletida nos baixos níveis de renda, algo que se explicita nas dificuldades que possuem no suprimento de suas necessidades de alimentação e saúde, uma vez que essas áreas concentram os maiores dispêndios realizados com o benefício. Os baixos valores repassados, mesmo assim importantes para as necessidades básicas, possuem uma valoração singular para essas famílias, mas também faz reluzir o nível de despossessão em que vivem.

Em relação ao fortalecimento do capital humano dos beneficiários, aspecto muito valorizado internacionalmente como variável de impacto, observou-se que, em São Felipe, o Programa não teve, na perspectiva dos beneficiários, grande impacto sobre a frequência e o rendimento escolar. Quanto aos serviços de saúde, muitas beneficiárias alegaram dificuldades no acesso, cujo problema é de responsabilidade do gestor público. Desse modo, ao invés investir tempo no controle da frequência das beneficiárias na saúde, o Estado poderia criar mecanismos para monitorar a acessibili荌 dade e a qualidade de seus serviços.

$\dot{a}$ estudo, em âmbito local, indica que talvez seja

iิ o momento de se repensarem as condiciona-

lidades, retirando o foco das beneficiárias e passando para os governos federados, que, em última instância, são os responsáveis pela melhoria da qualidade da saúde e da educação. Nesta proposta, a responsabilidade pelos fracassos não será das beneficiárias, mas recairá sobre o Estado.
A pesquisa ainda apontou a falta de articulação e planejamento integrado entre a educação, saúde e assistência social, não só para a gestão das condicionalidades, como também para o desenvolvimento e oferta de atividades específicas às famílias beneficiárias. Essa constatação, aliada às percepções declaradas pelas beneficiárias, reforça a crítica ao caráter inoperante das condicionalidades na melhoria da qualidade de vida. Em São Felipe, na Bahia, as condicionalidades pouco ajudam a cumprir os objetivos de fortalecimento do capital humano em longo prazo.

Nota-se um evidente descompromisso da gestão local do Programa com os objetivos de longo prazo do Bolsa Família, dada a falta de articulação entre as áreas e a falta de oferta contínua de programas complementares. Pelas informações colhidas, o município gere o Bolsa Família de maneira desarticulada, pois cada área administra as obrigações que lhe cabem sem que haja um objetivo traçado em conjunto. A gestão local se limita à operacionalização do Programa, alijando as potencialidades que o Bolsa Família enseja em termos de ganhos para as famílias, o que, de certo modo, explicita a percepção de que o benefício cumpre apenas o alívio da pobreza, até mesmo para o gestor local.

Considerando os resultados obtidos com a pesquisa empírica - perfil socioeconômico das famílias e avaliação de componentes da educação, saúde, assistência social e do Programa -, confirmou-se a hipótese de que o Bolsa Família, em âmbito local, funciona como um paliativo para as más condições de vida. Além disso, os governos são incapazes de promover ações complementares.

O benefício é de grande relevo para as famílias pobres. Entretanto, devido ao baixo valor do benefício e à falta de programas complementares, ele é incapaz, até o momento, de retirá-las da situação de pobreza. Além disso, erros de inclusão ainda são relevantes, motivo pelo qual muitos autores defendem a passagem do Bolsa Família para um programa de renda básica universal. Dentre as vantagens da 
renda básica está a possibilidade de as beneficiárias poderem combinar atividades laborais com o recebimento de benefícios.

Recebido para publicação em 19 de agosto de 2014 Aceito em 11 de dezembro de 2014

\section{REFERÊNCIAS}

ARRETCHE, Marta. Tendência no estudo sobre avaliação. In: RICO, Elizabeth Melo (Org.). Avaliação de políticas sociais: uma questão em debate. São Paulo: Cortez, p. 2940, 1998.

ÁVILA, Milene Peixoto. El Programa Bolsa Familia y la participación ciudadana: idas y vueltas. Revista Opera. Bogotá: Universidad Externado de Colombia, n. 10, p. 6782, 2010.

BICHIR, Renata Mirandola. O Bolsa Família na berlinda? Os desafios atuais dos programas de transferência de renda. Novos Estudos CEBRAP, São Paulo, v. 87, p. 114$129,2010$.

BRASIL. Ministério do Desenvolvimento Social e Combate à Fome. Programa Bolsa Família. Disponível em: http:/ www.mds.gov.br/bolsafamilia. Acesso: out./dez. 2012.

CASTIÑEIRA, Berta Rivera; NUNES, Luis Currais; RUNGO, Paolo. Impacto de los programas de transferencia condicionada de renta sobre el estado de salud: el Programa Bolsa Familia de Brasil. Revista Española de Salud Pública, v. 83 , n. 1, p. 85-97, 2009.

ESTRELLA, Juliana; RIBEIRO, Leandro Molhano. Qualidade da gestão das condicionalidades do Programa Bolsa Família: uma discussão sobre o índice de gestão descentralizada. Revista de Administração Pública. Rio de Janeiro, v. 42, n. 3, p. 625-641, 2008.

HEVIA DE LA JARA, Felipe Jose. La difícil articulación entre políticas universales y programas focalizados. Etnografía institucional del programa Bolsa Família de Brasil. Gestión y Política Pública. Cidade do México: Centro de Investigación y Docencia Económicas, v. 20, n. 02, p. 331-379, 2011b.

Relaciones Sociedad-Estado, participación ciudadana y clientelismo político en programas contra la pobreza. El caso de Bolsa Familia en Brasil. América Latina Hoy, Revista de Ciencias Sociales. Salamanca. v. 57, p. 205238, 2011a.

IBGE - INSTITUTO BRASILEIRO DE GEOGRAFIA E ESTATÍSTICA. Censo Demográfico 2010. Disponível em: http://www.ibge.gov.br/cidadesat/xtras/perfil.php? codmun $=292910 \& \mathrm{r}=2$. Acesso em: 04 dez. 2012.

KERSTENETZKY, Célia Lessa. Redistribuição e desenvolvimento? A Economia Política do Programa Bolsa Família. DADOS - Revista de Ciências Sociais. Rio de Janeiro. v. 52, n. 1, p. 53-83, 2009.

LICIO, Elaine Cristina; MESQUITA, Camile Sahb; CURRALERO, Claudia Regina Baddini. Desafios para a coordenação intergovernamental do Programa Bolsa Família. Revista de Administração de Empresas. São Paulo, v. 51, n. 5 , p. $458-470$, set./out. 2011.

LINDERT, Kathy; LINDER, Anja; HOBBS, Jason; BRIÈRE, Bènèdicte De La. The nuts and bolts of Brazil's Bolsa Família Program: implementing conditional cash transfers in a decentralized context. World Bank. (Discussion Paper, n. 709), 2007.

MARQUES, Rosa Maria. Política de transferência de renda no Brasil: a experiência do Bolsa Família. Sociedade e Cultura. Goiás: UFG. v. 11, n. 2, p. 237-243, jul/dez 2008.

MOURÃO, Luciana; JESUS, Anderson Macedo. Programa Bolsa Família: uma análise do programa de transferência de renda brasileiro. Field Actions Science Reports, Edição Especial 3, 2012. Disponível em: http://factsreports.revues. org/1319. Acesso em: 11 nov. 2012.

RUA, Maria das Graças. Análise de políticas públicas: conceitos básicos. In: RUA, Maria das Graças; CARVALHO, Maria (Org.). O Estudo da política: tópicos selecionados. Brasília: Paralelo 15, 1998.

SÃO FELIPE. Prefeitura Municipal de São Felipe. Secretaria Municipal do Trabalho e Accão Social. Relatórios de Gestão - 2009/2011. Acervo Público. Pesquisa realizada em 29 out. 2012.

Prefeitura Municipal de São Felipe. Secretaria Municipal de Administracão e Finanças. Mapa do município. 2007. Acervo Público. Pesquisa realizada em 12 jan.2011.

SANTOS, Cláudia Roberta Bocca; MAGALHÃES, Rosana. Pobreza e Política Social: a implementação de programas complementares do Programa Bolsa Família. Ciência \& Saúde Coletiva. Rio de Janeiro, v. 17, n. 5, p. 1215-1224, 2012

SILVA, Maria Ozanira Da Silva e (2010) Os limites da focalização e a transição para uma renda básica de cidadania. In: $13^{\circ}$ CONGRESSO INTERNACIONAL DA REDE MUNDIAL DE RENDA BÁSICA. Anais. São Paulo: Síntese Eventos, 2010.

SOARES, Fábio Veras; RIBAS, Rafael Perez; OSÓRIO, Rafael Guerreiro. Evaluating the Impact of Brazil's Bolsa Família: Cash Transfer Programs in Comparative Perspective. Latin American Research Review. Latin America Studies Association: v. 45, n. 2, p. 173-190, 2010.

SEI- Superintendência De Estudos Econômicos E Sociais Da Bahia. Estatística dos municípios baianos: território de identidade do Recôncavo. Salvador: SEI, v. 13, 2010.

VILLATORO, Pablo. Programas de transferências monetárias condicionadas: experiências na América Latina. Revista CEPAL - Número especial em português. Santiago do Chile: CEPAL, p. 127-141, 2010.

ZIMMERMANN, Clóvis Roberto. Política de renda mínima no Brasil: o Bolsa Família na ótica dos direitos humanos. In: $13^{\circ}$ CONGRESSO INTERNACIONAL DA REDE MUNDIAL DE RENDA BÁSICA. Anais.São Paulo: Síntese Eventos, 2010. 
SOCIAL PROGRAMS IN BRAZIL: a study on the Family Allowance Program in Brazilian Northeast countryside

Clóvis Roberto Zimmermann
Gepherson Macêdo Espínola

The Bolsa Família (Family Allowance) Program is the subject of some disagreement in Brazil, regarding the effect on poverty, value of the allowance, conditions to receive the allowance, inclusion errors, political benefits, "exit doors", among others. Due to this context, the intent of this article is to study Bolsa Família in a local level, from the recipients' perception. Finally, we discuss research results, which indicate a need for a higher investment in education and public health in Brazil. The study also suggests that maybe this is an appropriate moment to rethink the conditions for the allowances. Instead of controlling the recipients, governments should improve quality of health and education, as well as articulate supplementary programs, especially work programs.

KEYwords: Social programs. Evaluation. Family Allowance. Bolsa Família.

\section{PROGRAMMES SOCIAUX AU BRÉSIL: une étude du Programme de Bourse Familiale dans la campagne du nord-est brésilien}

\author{
Clóvis Roberto Zimmermann \\ Gepherson Macêdo Espínola
}

Le Programme Bourse Familiale fait toujours l'objet de divergences au Brésil, soit pour ses prémisses, soit en ce qui concerne la diminution de la pauvreté, la valeur de l'allocation, l'exigence de certaines conditions, les erreurs d'inclusion, le bénéfice politique, les "issues alternatives", entre autres. C'est pour toutes ces raisons que le présent article se propose d'étudier la Bourse Familiale à un niveau local, en se basant sur la perception des bénéficiaires. Au final, les résultats de la recherche sont analysés et indiquent le besoin d'investir plus au niveau de la qualité dans les domaines de l'éducation et de la santé publique brésilienne. Létude suggère aussi que le moment est peut-être venu de repenser ces inconditionnalités. Au lieu de contrôler les bénéficiaires, les gouvernements devraient améliorer la qualité de la santé et de l'éducation mais aussi implanter des programmes complémentaires et tout particulièrement ceux permettant l'accès au travail.

Mots-CLÉs: Programmes sociaux. Évaluation. Bourse Familiale.

\footnotetext{
Clóvis Roberto Zimmermann - Doutor em Sociologia pela Universidade de Heidelberg, Alemanha. Docente do Programa de Pós-Graduação em Gestão de Políticas Públicas e Segurança Social da Universidade Federal do Recôncavo da Bahia (UFRB). Coordenador do Programa de Pós-Graduação em Ciências Sociais da Universidade Federal da Bahia (UFBA). Publicações recentes: Combate à fome e miséria no governo Lula: garantia do direito à alimentação?. Revista Espaço Acadêmico (UEM), v. 11, p. 135-142, 2012; Noch kein neuer Sozialvertrag: trotz wirtschaftsboom und der Regierungsprogramme Bolsa Família und Brasil Sem Miséria bestehen Hunger und extreme Armut in Brasilien fort. LateinamerikaNachrichten. v. 456, p. 41-45, 2012; Noch kein neuer Sozialvertrag. Brasilien-Nachrichten, v. 145, p. 20-21, 2012.

Gepherson Macêdo Espínola - Mestre em Gestão de Políticas Públicas e Segurança Social pela $\dot{2}$ Universidade Federal do Recôncavo da Bahia (UFRB). Tem experiência na área de Economia Social e de gestão de Politicas Públicas, além de participação em conselhos de Controle Social - Saúde, Direitos da - Criança e do Adolescente, Assistência Social e Cidade. Tem interesse, sobretudo, nos seguintes temas: políticas públicas, políticas sociais, pobreza, desigualdade e análise socioeconômica. Em 2014, foi premiado no XX Prêmio Brasil de Economia, na categoria dissertação de mestrado, pelo trabalho intitulado "Bolsa Família: uma análise a partir da percepção dos beneficiários de São Felipe - BA". Publicações recentes: Programas de transferência de renda e desenvolvimento socioeconômico: o desenvolvimento pela ótica dos beneficiários do Programa Bolsa Família em um município brasileiro. In: V Congresso Anual - Asociación de Economia para el Desarrollo de la Argentina: Nuevas e viejas restricciones al desarrollo. Contribuciones de la Economía Política para superarlas, Buenos Aires - Argentina. Anais 2013; Inovações: formação e desafios para Brasil. In: V Congresso Anual - Asociación de Economia para el Desarrollo de la Argentina: Nuevas e viejas restricciones al desarrollo. Contribuciones de la Economía Política para superarlas. Buenos Aires - Argentina. Anais, 2013.
} 